\title{
O sistema industrial localizado de calçados de Franca (SP) e sua nova configuração urbano regional
}

Le système industriel localisé de chaussures de Franca (SP) e sa-nouvelle organisation urbaine régionale

El sistema industrial localizado de calzados de Franca (SP) y su nueva configuración urbana regional

The Franca's located industrial system of footwear and its new regional urban organization

\section{José Eudázio Honório Sampaio e Edilson Alves Pereira Júnior}

\section{(2) OpenEdition}

\section{Journals}

Edição electrónica

URL: http://journals.openedition.org/espacoeconomia/5433

DOI: $10.4000 /$ espacoeconomia.5433

ISSN: 2317-7837

\section{Editora}

Núcleo de Pesquisa Espaço \& Economia

\section{Refêrencia eletrónica}

José Eudázio Honório Sampaio e Edilson Alves Pereira Júnior, « O sistema industrial localizado de calçados de Franca (SP) e sua nova configuração urbano regional », Espaço e Economia [Online], 14 | 2019, posto online no dia 10 agosto 2019, consultado o 05 setembro 2019. URL : http:// journals.openedition.org/espacoeconomia/5433 ; DOI : 10.4000/espacoeconomia.5433

Este documento foi criado de forma automática no dia 5 Setembro 2019

(c) NUPEE 


\title{
O sistema industrial localizado de calçados de Franca (SP) e sua nova configuração urbano regional
}

\author{
Le système industriel localisé de chaussures de Franca (SP) e sa-nouvelle \\ organisation urbaine régionale \\ El sistema industrial localizado de calzados de Franca (SP) y su nueva \\ configuración urbana regional \\ The Franca's located industrial system of footwear and its new regional urban \\ organization
}

José Eudázio Honório Sampaio e Edilson Alves Pereira Júnior

\section{Introdução}

1 Nas últimas décadas a dinâmica que envolve a produção industrial calçadista passa por transformações significativas. Isso ocorre, entre outros fatores, em função da necessidade sentida pelas empresas em contornar as instabilidades do mercado produtivo, resultando em tentativas de redução de custos por meio de inovações tecnológicas e reengenharias de produção. São modificações articuladas à reestruturação territorial e produtiva, cujos impactos estimulam a flexibilização da produção, o aumento da subcontratação nas relações de trabalho, a disjunção funcional e a ampliação dos circuitos espaciais produtivos e de consumo.

2 A indústria de calçados, desse modo, está cada vez mais submetida a uma difusa rede de relações territoriais que integram pessoas, mercadorias e capital, incorporando mudanças diretamente vinculadas à engenharia produtiva e à abrangência espacial de seu mercado consumidor. Tais alterações engendram transformações quantitativas e qualitativas, atingindo a distribuição de estabelecimentos industriais no interior das regiões produtivas tradicionais ou em áreas anteriormente consideradas periféricas e distantes. 
Como consequência, antigas regiões industrializadas atravessam importantes modificações, principalmente ao adotar um projeto de acumulação pautado na redução de custos, consolidando uma reestruturação urbano regional como condicionante estratégico de dinamização produtiva. No caso de Franca, no estado de São Paulo, temos um Sistema Industrial Localizado (SIL) originado em meados do século XIX e consolidado na década de 1970 que sofre importantes mudanças, sobretudo àquelas ligadas às novas formas de organização da produção e seus impactos sobre o espaço urbano regional.

Buscamos, neste artigo, compreender como a região de influência deste SIL passa a ser utilizada como medida de competitividade, a partir da flexibilização da produção e da precarização do trabalho. Para tanto, algumas atividades teórico-metodológicas foram montadas para compor a base da pesquisa, quais sejam: a) um levantamento bibliográfico, com base nas discussões de reestruturação produtiva e territorial, Sistema Industrial Localizado (SIL) e organização da produção e relações de trabalho; b) uma consulta documental e estatística, feita em instituições como Associação Brasileira das Indústrias de Calçados (ABICALÇADOS), Sindicato da Indústria de Calçados de Franca (SINDIFRANCA) e Ministério do Trabalho e do Emprego (MTE); e c) trabalho de campo, com foco para a articulação das estratégias das empresas e dos demais agentes que compõem o SIL, no âmbito da região de influência da cidade de Franca.

O artigo é composto por esta introdução e outros itens que vão tratar de temáticas como reestruturação produtiva e territorial, sistemas industriais localizados e impactos urbano regionais dos sistemas de produção. Após discutir os temas particularmente e nas relações que podem ser estabelecidas entre eles, o debate será conduzido à análise final.

\section{Reestruturação produtiva e territorial e o papel dos sistemas industriais localizados}

6 As alterações ligadas aos mercados globais de produção e consumo de massa criaram uma crise no fordismo no último quartel do século XX. Muitas interpretações realizadas acerca das aglomerações industriais, desde a década de 1970, já apontavam o importante papel de um novo encadeamento industrial, mediante o processo de reestruturação que ganharia maior representatividade nos anos de 1990.

Isso resultou numa nova divisão internacional do trabalho, que também marcou a reconfiguração do entrelaçamento de estratégias entre empresas, Estados e territórios (LIPIETZ, 1988). A partir de então, passou a ser essencial o entendimento do conceito de flexibilidade na produção industrial, em especial para designar uma série de efeitos produtivos diferentes, em que os principais elementos são: a organização do processo de trabalho, a hierarquia das qualificações, a mobilidade dos trabalhadores, o princípio da formação dos salários e a utilização da renda salarial (BENKO, 1999).

8 Esse é um período em que o mercado, mediante o desenvolvimento da ciência, da técnica e da própria informação, se torna amplo e de alcance mundial (SANTOS e SILVEIRA, 2013) e as relações financeiras estão na base dos princípios universais da acumulação e dos deslocamentos, atingindo as esferas da produção e circulação de riquezas (MENDÉZ, 2018). Ao mobilizarem um conjunto de agentes econômicos e governamentais capazes de levar o sistema com frequência a um novo arranjo, as normas estabelecidas na busca da rentabilidade máxima ultrapassam as relações eminentemente financeiras e tomam forma num novo mundo industrial (VELTZ, 2008). 
9 Isso costuma ocorrer quando investidores financeiros exercem pressões sobre empresas produtivas, principalmente as de sociedade aberta. A generalização do princípio da competitividade para todas as empresas é reflexo da mudança estabelecida na atividade industrial, ao tomar para si as metas e os ritmos da acumulação com dominação financeira (PEREIRA JÚNIOR, 2012).

10 A financeirização passa a ser vista num novo contexto, ligada ao neoliberalismo, possibilitando crescimento da rentabilidade a partir da difusão global dos investimentos. Estes, a priori, são monetários, mas logo se vincularão às decisões do mundo produtivo e da política. O aparecimento da dominação financeira, como destaca Mendéz (2018), impacta diretamente no funcionamento e na organização das empresas que, ao abrirem capital na bolsa de valores, com o objetivo de obter maiores rendimentos a curto prazo e revalorizar suas ações, impulsionam a segmentação dos processos de produção.

11 Neste sentido, é notável o aumento da multiplicação da externalização e da relocalização de tarefas, com o objetivo de reduzir custos, elevar os benefícios das empresas, mas também, melhorar a produtividade pela via da diminuição dos gastos. A ideia é reduzir a inércia das empresas no território e, assim, aumentar a divisão regional da produção. Ao mesmo tempo, o impacto é sentido sobre o trabalho, com precarização cada vez maior das relações laborais.

12 No contexto dessa reestruturação do controle do trabalho, marcada pela dispersão produtiva e geográfica, os reflexos se encontram na divisão técnica dos processos produtivos, sobretudo ao incrementar novos lugares aos circuitos espaciais da produção (PEREIRA JÚNIOR, 2012). Esta nova racionalização das formas de acumulação continua sendo gerada pela apropriação do trabalho no processo produtivo, mas agora as estratégias de compartimentação, divisão das funções e articulação das atividades de produção estão muito mais complexas. Por este motivo a empresa flexível exige dos que trabalham uma total adesão ao espírito da empresa, conciliando estratégias capitalistas e pré-capitalistas, simultaneamente, tanto em etapas de produção como de circulação e de consumo.

13 Para Soja (1993) a reestruturação possui fortes relações com a mudança no ordenamento e configuração da vida local, econômica e política, mas não é um processo mecânico. Ela é uma mescla de experiências, e neste sentido antigos e novos elementos passam a ser ajustados, estimulando as empresas industriais a incorporarem práticas renovadas, da mesma maneira em que, contraditoriamente, mantêm características tradicionais.

14 Neste artigo, então, a reestruturação não é lida apenas como uma força produtiva, mas se coloca, especialmente, por sua extensão territorial. De acordo com Pereira Júnior (2012), ela aparece como uma inovação na produção, mediante a incorporação de conquistas gerenciais e tecnológicas, mas se completa através das estratégias territoriais, sobretudo graças às possibilidades de difusão das etapas de fabricação no espaço geográfico. Teremos, então, os planos de engenharia superando a variável distância e passando a aproveitar vantagens regionais, eliminando problemas com a pressão sindical ou com a ociosidade de estoques, máquinas e componentes (PEREIRA JÚNIOR, 2015).

Por este motivo, as empresas passam a fazer uso de estratégias de ajustamento no espaço. Como ressalta Fischer (1994), essas estratégias podem ser divididas em: 1) uma desintegração interna, relacionada ao fracionamento produtivo e de seu plano funcional; e 2) a relocalização industrial, a partir da externalização da produção e da ampliação das relações de subcontratação. 

da unidade produtiva e das próprias firmas que a administram, o que leva ao redescobrimento das possibilidades de absorção produtiva da região através da subcontratação e do controle de pequenos estabelecimentos, representados por agentes modestos, com menor poder de decisão.

17 A emergência de modelos de sistemas produtivos fraturados, com fortes relações com o dinamismo endógeno de coletividades locais, a partir da justaposição com formas fordistas, é uma característica da geografia industrial do presente. Ela valoriza a sinergia e a cooperação e, ao mesmo tempo, transforma a organização econômica do sistema produtivo, destacando o papel das micro e pequenas empresas na efetivação das medidas de flexibilidade.

modo, a nova lógica industrial materializa desenvolvimento endógeno e aglomeração de empresas, respondendo às demandas por competitividade e redução de custos nos processos produtivos. É a maneira encontrada para atender o desafio da expansão dos lucros nos setores produtivos, uma clara consequência da nova realidade de acumulação com predominância financeira, a envolver agentes econômicos, sociais e políticos nesta nova escalada de concorrência internacional.

\section{Os sistemas industriais localizados no contexto}

As estruturas produtivas, ao apresentarem características descentralizadas e favoráveis às relações de solidariedade entre os agentes de uma determinada região, passam a dar ao ambiente local múltiplas possibilidades de resposta às demandas produtivas e financeiras contemporâneas, estimulando uma industrialização difusa.

Neste aspecto, o "local" passa a estar articulado com processos globais de regulação econômica e se apresenta como um espaço de mediação entre várias escalas, articuladas por um esquema relacional. Como destacado por Benko (1999), o desafio está em estabelecer e definir novos contornos entre a divisão inter-regional (internacional) do trabalho e o desenvolvimento endógeno, sobretudo pela possibilidade da articulação transescalar das análises.

21 Esta discussão ganha destaque a partir dos trabalhos publicados sobre a "Terceira Itália", com a articulação entre concorrência/emulação/cooperação (BECATTINI, 1979) e a aglomeração de pequenas e médias empresas. $O$ que é importante, neste sentido, é o destaque dado à organização produtiva, a partir de uma divisão técnica do trabalho e das relações transacionais inter firmas. Neste aspecto, a nova geografia da produção obedece a uma renovada lógica territorial, por meio de uma divisão espacial do trabalho mais ampla, desverticalizada, e da formação de regiões flexíveis, em resposta às demandas da globalização.

es agrupamentos empresariais territorializados recebem diversas nomenclaturas, pois indicam um fenômeno com características parecidas, mesmo demarcando algumas diferenças de ajustamento. Podem ser conhecidos como "distritos industriais", "clusters", "arranjos produtivos locais", "ambientes inovadores", "sistemas produtivos locais", "sistemas industriais localizados", entre outros. Todos eles estão relacionados a uma leitura das concentrações de empresas, de um ou vários ramos, em determinada região. Mas também é possível haver uma multiplicidade de economias territorializadas que não são guiadas por uma transformação abrangente. Como destaca Reis (1992) e Pyke e 
Sengerberger (1992), as economias territorializadas não são idênticas, possuem variações no que diz respeito à cultura local, alianças políticas, níveis de habilidade, tecnologia, relações entre empresas e instituições.

O termo arranjo ou sistema produtivo local (APL), foi o que ganhou maior relevância e divulgação no Brasil. A Rede de Pesquisa em Sistemas e Arranjos Produtivos Inovativos e Locais (REDESIST), criada em 1997, é o destaque nos estudos desses agrupamentos empresariais territorializados. Em 2010, o Ministério da Integração, por meio da Política Nacional de Desenvolvimento Regional, realizou um trabalho em conjunto com o Governo do Estado do Pará, por meio do Instituto de Desenvolvimento Econômico, Social e Ambiental do Pará (IDESP), buscando ampliar a compreensão do papel dos APLs, principalmente no momento da ascensão das atividades produtivas flexíveis (COSTA, 2010).

25 Segundo o estudo, o termo APL surge como uma espécie de "guarda-chuva", capaz de abrigar a diversidade do fenômeno, mas que apresenta um elemento de coesão entre todos os conceitos propostos, isto é, a construção de um instrumento de política econômica. Torna-se assim, um espaço social, econômico e historicamente construído por uma aglomeração de empresas, fortemente relacionadas ou interdependentes, que interagem em escala local com fluxos de bens e serviços.

Suzigan et. al. (2004), destaca que os sistemas locais de produção existentes no Brasil desenvolveram de forma limitada os mecanismos de cooperação. Isso é um problema, pois essa habilidade se constituiu a base dessas configurações em outros países, sobretudo na Itália, na Alemanha e na França. Nesse sentido, as políticas de fomento e promoção dos APLs enfrentam dilemas múltiplos, especialmente porque devem ser potencialmente democráticas, e na maioria dos casos, devem priorizar a importância de pequenas empresas em regiões não metropolitanas, vinculadas a tecidos econômicos e sociais não hegemônicos.

27 A realidade desses aglomerados no estado do Ceará, já estudada por Pereira Júnior (2012), demonstra bem a inadequação do conceito de Arranjo Produtivo Local (APL) para as experiências investigadas. A desarticulação entre agentes e a presença insignificante do elemento cooperação na "engrenagem" dos arranjos, leva o autor a preferir utilizar o conceito de Sistema Industrial Localizado (SIL) para classificar esse tipo de aglomeração produtiva.

O conceito de SIL foi trabalhado, entre outros, por Reis (1992; 2004), que o interpreta como o resultado de um aglomerado regional ou local de empresas concentradas em torno de um ou vários gêneros industriais, com ou sem cooperação produtiva e comercial. Nesses SILs são expressivas as relações de vida local e de produção industrial com padrões de organização ligados aos referenciais localizados de acumulação, mas o que os torna diferentes dos arranjos produtivos locais é exatamente a falta de uma convergência em termos de desenvolvimento. No conjunto dos sistemas industriais localizados, mesmo ao aproveitar amenidades territorialmente tecidas, os agentes acabam não tirando vantagens de estratégias cooperativas.

A análise realizada por Reis (1992; 2004), está pautada em uma organização de difusão industrial e desenvolvimento intermédio e não metropolitano. Neste caso, as circunstâncias que caracterizam o sistema produtivo possuem especificidades em relação às outras formas de desenvolvimento local. Porém, continuam predominando o sistema 
de pequenas empresas, a especialização produtiva, a divisão local do trabalho industrial e as sinergias locais.

Para que um sistema industrial localizado (SIL) prospere é preciso que não esteja controlado exclusivamente pela dinâmica ou pelos agentes da globalização (REIS, 2004). Também é necessário haver mecanismos internos de coordenação do sistema, que possam oferecer uma resposta satisfatória aos desafios que os agentes locais irão enfrentar. Da mesma maneira, precisam estar atrelados à fluxos externos, tecnológicos ou de mercado $\mathrm{e}$ ao movimento que ocorre fora da região para não se fragilizarem por limitações endógenas. Portanto, precisam se apresentar como mediação entre os efeitos da globalização, as políticas nacionais e as ações locais.

Segundo Moraes e Schneider (2011), o desenvolvimento territorial é resultado de ações e reações dos agentes sociais, das instituições e das sociedades locais, que tentam conduzir as atividades aproveitando os fatores produtivos disponíveis no próprio território. Ou seja, seu potencial é endógeno, mas precisam aproveitar oportunidades externas favoráveis que se renovem com eficiência.

Quando isso não ocorre e os SILs não têm capacidade de se renovar, não se abrindo às vantagens da inovação e da articulação em muitas escalas. Há tendência a um esgotamento do sistema produtivo, que se traduz através de várias manifestações, entre as quais podemos citar: a) a desvalorização do principal produto negociado; b) a concorrência predatória entre os agentes do aglomerado; c) a fragilidade face aos agentes comerciais e financeiros de intermediação; d) a perda de produtividade; e) a diversificação para outros ramos produtivos.

33 Ao ser submetido às forças exógenas da globalização, sem qualquer mediação com os agentes localizados, têm-se a materialização da reestruturação produtiva e territorial que desqualificam as regiões e suas principais possibilidades. Trabalho, produto e agentes locais se enfraquecem, embora o aglomerado tenha participação na concorrência e na competitividade nacional ou global.

maneira, as novas economias e deseconomias não podem, como destaca Trigilia (1992), ser tratadas apenas no nível local. Ao esbarrarem nos problemas de escala e na falta de recursos, passa a existir uma necessidade de maior integração na organização regional e não apenas local. A ameaça está nas novas articulações internacionais, na competição e nas dificuldades que os sistemas têm em manter sua eficiência. É necessário haver medidas pelas autoridades locais e sindicatos, para evitar a degeneração de áreas em decadência relativa e exploração laboral.

Obviamente, manifestações das duas tendências, isolamento ou submissão irrestrita, também podem se dar em determinado sistema localizado, implicando muitas vezes na ação predatória de vários agentes, que esgotam inúmeras possiblidades locais. Tudo isso irá se manifestar nos territórios com altíssimos custos sociais, cujos principais prejudicados serão os trabalhadores ou os pequenos produtores, incapazes de demonstrar força face à ação de agentes hegemônicos. Também é importante perceber que até mesmo grandes empresas de origem local podem perder quando esse descompasso entre o local e o global se estabelece.

36 A resistência de determinadas economias territorializadas, mesmo sob forte competitividade internacional, é possível com o fortalecimento de uma economia local em rede. A disjunção funcional (FISCHER, 1994), as tecnologias de informação e a divisão regional do trabalho completam o quadro, demarcando os rumos da expansão capitalista 
industrial. Vejamos como isso passou a se estruturar no sistema industrial localizado calçadista de Franca (SP).

\section{A nova organização do Sistema Industrial Localizado de Calçados em Franca (SP)}

37 A indústria calçadista brasileira, desde a década de 1990, passa por alterações em sua organização territorial, sobretudo por ter reconfigurado seu mapa de produção no âmbito nacional, ao inserir os estados nordestinos no circuito produtivo e ter forçado as regiões produtoras tradicionais a buscarem novas estratégias de competitividade.

O sistema industrial localizado de calçados masculinos de couro em Franca (SP) é o mais tradicional do estado de São Paulo ${ }^{1}$. Está situado na Região Administrativa de Franca, a aproximadamente $400 \mathrm{~km}$ da capital. Ainda hoje, representa o maior aglomerado de produção de calçados masculinos de couro do Brasil, com 1.456 estabelecimentos industriais calçadistas, sendo a maior parte deles formado por micro e pequenos estabelecimentos, geradores de 16.713 empregos formais em 2017 (MTE/RAIS, 2018). No ano de 2018, Franca produziu 26,8 milhões de pares, sendo 1,2 milhões exportados para mais de 60 países, sobretudo Estados Unidos e Argentina, arrecadando US\$ 67.373.725,00 (SINDIFRANCA, 2019).

39 A produção no município foi iniciada em meados do século XIX e consolidada na década de 1970, principalmente a partir do atendimento ao mercado externo, juntamente com as empresas produtoras de calçados da região do Vale dos Sinos (RS). No entanto, desde os anos de 1990, a partir da abertura econômica aos investimentos internacionais e da chegada de produtos de outros países a preços mais competitivos, o SIL passa por modificações, especialmente no que diz respeito à sua organização produtiva e de trabalho.

Com as mudanças, uma série de dificuldades passaram a ser sentidas, porque as empresas passaram a adequar a produção à uma lógica mais flexível. Engendrou-se uma nova divisão do trabalho e os padrões de organização tecnológica foram ampliados. Embora tenha havido um incremento do Just-in-time, programas de controle de qualidade total, inserção de microeletrônica (CAD/CAM) e informatização da produção, a principal mudança no SIL esteve atrelada ao aumento da jornada de trabalho. De igual maneira, houve redução no número de trabalhadores formais, efetivando-se uma reorganização das atividades a partir da terceirização e externalização de etapas da produção.

Como destaca Navarro (2006), isso está associado a uma redução dos custos de produção, com resultado direto na intensificação do trabalho, na diminuição dos salários e no aumento da informalidade. As empresas passaram a estabelecer, segundo Braga-Filho (2000), uma flexibilização interna e externa da produção. A primeira se dá a partir da redução dos níveis hierárquicos (desverticalização da produção), ao tornar a produção mais leve e enxuta, aumentando a produtividade quando reduz os custos de mão de obra. A segunda, por sua vez, se efetiva na transferência de sua produção, ou alguma etapa dela, para outras firmas, com a intenção de não arcar com os custos e a responsabilidade pela mão de obra (encargos sociais e trabalhistas).

Importantes instituições, típicas de arranjos territorializados que geram economias externas, se encontram em Franca. No entanto, coexistem e crescem novos processos ligados ao aumento da informalidade e à diversificação do antigo produto símbolo da 
indústria local, o calçado masculino de couro. Assim, associado ao clássico sapato de couro masculino, atualmente, a produção se dá com o uso de diferentes materiais, como tecido, plástico e couro sintético, além de produzir para outros públicos, como calçados femininos e infantis.

Ademais, durante a realização do trabalho de campo, em 2019, inúmeros entrevistados informaram que o município passa por uma diversificação no que diz respeito ao seu setor produtivo, uma vez que o calçado de couro não é mais capaz de sustentar as fábricas. Por este motivo, muitas empresas passam a produzir calçados femininos, bolsas, cintos, ou ainda, diversificam sua produção com fabricação de diferentes materiais, como confecções de roupa íntima feminina.

As mudanças nos últimos anos acarretaram uma rearticulação do circuito espacial da produção na escala da região. Uma nova organização da produção foi estabelecida, já que é crescente a produção especializada em determinadas etapas produtivas. No caso das empresas tradicionais, como é o caso da Sândalo e da Samello, praticamente toda a produção foi transferida para produtores subcontratados, sendo que elas concentram apenas a gestão e a comercialização do produto finalizado.

Assim, desde a década de 1990, foi possível notar um aumento do número de bancas (formais e informais) ${ }^{2}$ e do trabalho em domicílio, ou ainda, o deslocamento das mais diversas linhas de produção para outros municípios da região, seja no estado de São Paulo ou em Minas Gerais.

Ao analisarmos os dados de estabelecimentos e vínculos na indústria calçadista em Franca nos anos de 1990 e 2017, por porte de empresa (como expressados nas imagens 1 e 2, a partir das tabelas correspondente ao número de estabelecimentos e empregos formais), compreendemos como se deu o movimento de desintegração vertical e disjunção funcional da produção.

Os estabelecimentos industriais no ano de 1990 totalizavam 769, sendo que 83\% destes, isto é 640 , correspondiam aos estabelecimentos de porte micro. Os pequenos estabelecimentos correspondiam a $9 \%$ (71), os médios a 7\% (49) e os grandes a $1 \%$ (09). Ao analisarmos o ano de 2017, notamos o aumento de 769 para 1.456, crescimento de cerca de $90 \%$ em 27 anos. Desse total, os micro estabelecimentos apresentaram crescimento de $100 \%$ (640 para 1.281) e agora representam $88 \%$ do total de unidades formais. Enquanto isso, os pequenos estabelecimentos evoluíram 115\% (71 para 153) e representam em 2017, $10,5 \%$ do total.

Imagem 1, tabela com o número de estabelecimentos na indústria calçadista de Franca (1990 e 2017)

\begin{tabular}{|c|c|c|c|c|c|c|c|c|c|}
\hline \multicolumn{5}{|c|}{ Porte do estabelecimento* -1990} & \multicolumn{5}{|c|}{ Porte do estabelecimento* -2017} \\
\hline Micro & Pequeno & Médio & Grande & Total & Micro & Pequeno & Médio & Grande & Total \\
\hline 640 & 71 & 49 & 09 & 769 & 1.281 & 153 & 20 & 02 & 1.456 \\
\hline
\end{tabular}

Fonte: MTE/RAIS, 2018. Elaborado pelos autores.

*Microempresa: até 19 empregados; pequena empresa: de 20 até 99 empregados; média empresa: de 100 até 499 empregados; e grande empresa: acima de 500 empregados.

Em contrapartida, os médios e grandes estabelecimentos apresentaram decréscimo no período analisado. Os primeiros caíram de 49 para $20(-60 \%)$ e passaram a representar apenas $1,3 \%$ do total, enquanto os grandes caíram de 9 para 2 estabelecimentos $(-78 \%)$, correspondendo, atualmente, a menos de $1 \%$ do todo. 
Imagem 2, tabela com número de empregos formais na indústria de calçados de Franca (1990 e 2017)

\begin{tabular}{|c|c|c|c|c|c|c|c|c|c|}
\hline \multicolumn{5}{|c|}{ Porte do estabelecimento* -1990} & \multicolumn{5}{|c|}{ Porte do estabelecimento* -2017} \\
\hline & & & & Tot & & & & Grande & al \\
\hline 1.96 & 136 & 9.801 & 7.047 & 21.949 & 4.371 & 6.557 & 4.430 & 1.355 & 16.713 \\
\hline
\end{tabular}

Fonte: MTE/RAIS, 2018. Elaborado pelos autores.

*Microempresa: até 19 empregados; pequena empresa: de 20 até 99 empregados; média empresa: de 100 até 499 empregados; e grande empresa: acima de 500 empregados. regionalmente, deslocando sua produção para muitos municípios de São Paulo e Minas Gerais, contando com a participação de micro e pequenas empresas especializadas na produção de partes do calçado, definindo uma nova configuração urbano regional do sistema produtivo. 


\section{Difusão regional da atividade industrial como estratégia competitiva}

O circuito produtivo de calçados de Franca passa a ter um caráter multi e transescalar, envolvendo uma densa rede de relações que articulam os estados do Nordeste do Brasil e vários municípios paulistas e mineiros no processo de produção; e vários estados do Brasil e outros países, no que tange ao consumo. Isso ocorre por meio de etapas produtivas instaladas no Ceará e na Bahia, mas também, ao utilizar a região de influência direta como suporte para obtenção de maiores taxas de lucratividade, em especial na fronteira dos estados de São Paulo e Minas Gerais.

Esta alteração na organização produtiva e do trabalho se estabelece com a difusão parcial ou total da produção para empresas subcontratadas. Logo, forma-se não apenas uma concentração, mas uma centralização do comando e da gestão da atividade calçadista regional por Franca. Isso ocorre porque quem define as relações são as grandes empresas, e estas permanecem localizadas na sede municipal, embora a produção esteja dispersa no território brasileiro e na região de influência da cidade.

Desse modo, um novo quadro produtivo regional se configura. Mas o interessante nesse processo é que os municípios que estão diretamente relacionados à produção de calçados em Franca são, em sua maioria, do estado de Minas Gerais. Os dados referentes aos municípios localizados na divisa entre os estados de São Paulo e Minas Gerais, e polarizados por Franca, permitem identificar que houve, durante a década de 1990, dispersão espacial dos estabelecimentos e dos empregos formais, como mostra a Imagem 3.

No intuito de organizar uma análise da centralidade de Franca em São Paulo e Minas Gerais, elaboramos uma relação de sua capacidade de concentração nos dois estados. Assim, se Franca, em 1990, polarizava pouco mais de 19\% dos estabelecimentos nos dois estados, a partir de 2017 essa polarização subiu para 40\% dos estabelecimentos.

Embora a representação dos outros municípios da região fique em cerca de 1\% do total, há crescimento considerável no período analisado. Isso nos faz concluir, que nos últimos 25 anos, a "mancha regional" da produção industrial sob influência direta de Franca se expandiu.

Da mesma forma, demonstra um movimento de aglomeração espacial em torno da cidade de Franca, a partir de 2017. Nos anos de 1990, a "mancha" tinha outra morfologia, quando a quantidade de estabelecimentos e empregos nos calçados estava mais fragmentada por diversos municípios mineiros e paulistas, com maior incidência para estes últimos. É nítida a formação de uma região mais aglomerada, capitaneada por Franca. 
Imagem 3, mapa da concentração de estabelecimentos e vínculos empregatícios da indústria calçadista na divisa de São Paulo com Minas Gerais (1990 - 2017)

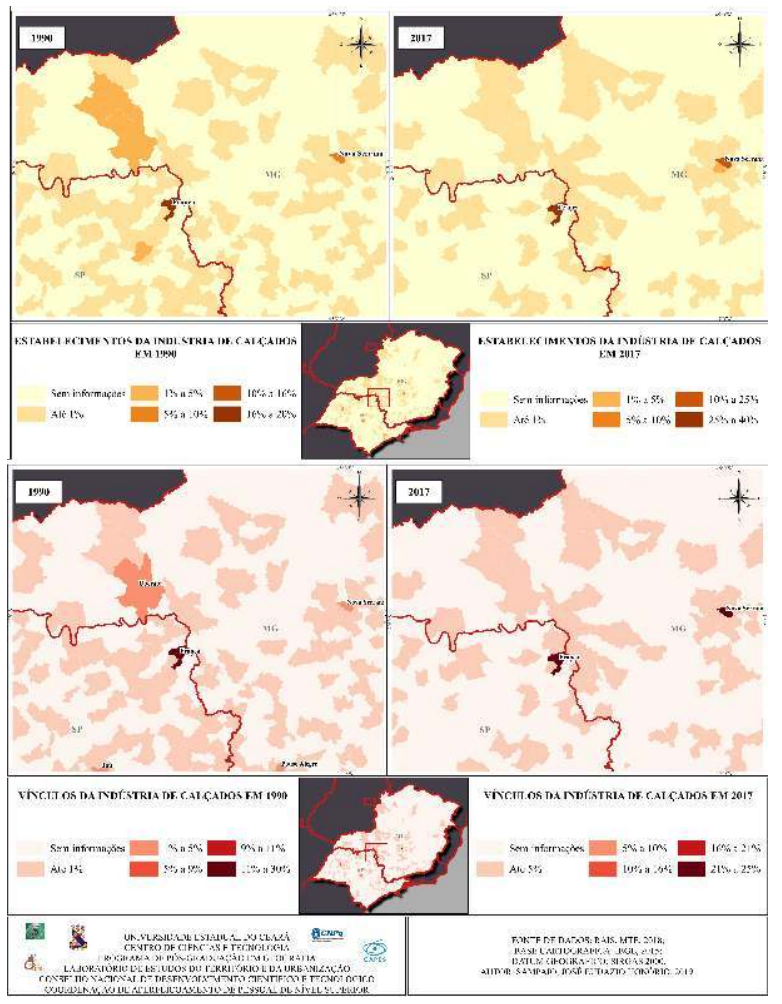

61 Enquanto Franca passou de 21.949 vínculos para 16.713, entre 1990 e 2017, a região em destaque, passou de 1.476 para 1.604, chegando, no ano de 2010, a 3.284 empregos formais gerados. No que diz respeito aos estabelecimentos, entre 1990 e 2017, Franca apresentou aumento de 769 para 1.456, enquanto a região passou de 101 a 110, mas chegou em 2010 a reunir 136 unidades de produção.

Esse movimento fortalece a ideia de que a diferença entre os territórios se dá pela capacidade que eles têm de oferecerem lucratividade diversa aos muitos tipos de investimentos (PEREIRA JÚNIOR, 2012). Tal lucratividade pode ser influenciada por condições locais, tanto de ordem técnica como em equipamentos, infraestrutura, acessibilidade, base organizacional, leis, impostos, relações trabalhistas e tradição laboral. Desta maneira, entram em questão também as infraestruturas como fator de decisões para determinados investimentos.

As empresas de Franca, nesse contexto, usam a região como mecanismo de competitividade, extraindo vantagens nos custos de produção. Assim como em outras relações estabelecidas entre empresas e região, nesse caso também é possível destacar fatores de atração importantes, tais como: a) incentivos fiscais ${ }^{4}$; b) preço pago pela força de trabalho ${ }^{5}$ (tratam-se de municípios pobres, com tradição rural); c) fornecimento de infraestrutura (as empresas são atraídas por terrenos baratos, doação de lotes ou a própria construção de galpões); d) transporte das partes do calçados para serem montados no município (feito por carros das prefeituras municipais); e, por fim, e) a falta de cobertura sindical dos trabalhadores dos municípios mineiros em relação às empresas de Franca. 
64 Nesse sentido, a discussão sobre a regionalização da produção calçadista ganha destaque, uma vez que relações produtivas ali estabelecidas subvertem os limites políticos administrativos. Em geral, a atração de filiais dessas empresas, bancas, ou o direcionamento de trabalho familiar e informal, refletem na diminuição dos empregos formais em Franca.

65 Confirma-se então, o fato de que algumas empresas de Franca passam a fazer uso da região para produzir partes do calçado, já que a produção retorna à cidade para ser finalizada e encaminhada aos mercados de consumo. Evidenciamos que este processo é realizado também por médias e grandes empresas, algumas delas já presentes em estados do Nordeste (como Democrata, Rafarillo e Sapatoterapia, no Ceará; e, Freeway e Ferracini, na Bahia). Quando a empresa busca instalação nos municípios mineiros, envia um gerente para treinar os trabalhadores, algo similar com o que ocorre com as empresas direcionadas ao Nordeste.

Os municípios diretamente relacionados com a produção de Franca conformam um sistema industrial localizado, bem articulado em nível transescalar. Fazem parte, em São Paulo, Batatais, Cravinhos, Cristais Paulista, Guará, Itirapuã, Jardinópolis, Jeriquara, Pedregulho, Restinga, Ribeirão Preto, São Joaquim da Barra e São José da Bela Vista. Em Minas Gerais, Araxá, Capetinga, Cássia, Claraval, Delfinópolis, Ibiraci, Passos, Piumhi, Pratápolis, Sacramento, São Roque de Minas, São Sebastião do Paraíso e São Tomás de Aquino. Eles agora são base da produção de muitas empresas de calçados de Franca.

67 A resistência do SIL de calçados de Franca demarca o Multicomplexo Territorial da indústria do estado de São Paulo (SELINGARDI-SAMPAIO, 2009). Ele tem uma construção social e histórica produzida por seus agentes, com diversidade de ações de produção integrada ou não. Mas a resistência deste SIL não é possível sem a incorporação de processos ligados à disjunção funcional, a partir da dispersão da produção na região e no território, conformando uma rede de relações e uma cadeia de valor que envolvem micro e pequenas empresas, sempre comandadas por agentes localizados na cidade de Franca.

É uma dispersão associada à busca por maior competitividade, através da diminuição de custos produtivos, o que implica numa tendência à redução do porte de empresas, que passam a se especializar em apenas determinadas etapas da produção. Nessa engenharia, as estratégias de flexibilidade são fundamentais e incluem subcontratação de "bancas", trabalho domiciliar, produção informal e desincompatibilização com as responsabilidades laborais, em especial em municípios da periferia da região. No âmbito desse novo arranjo, a dimensão territorial continua sendo a chave para a reprodução das taxas de lucratividade e seu papel na manutenção dos sistemas localizados ganha cada vez mais centralidade.

\section{Conclusão}

69 As mudanças recentes nas formas de organização econômica, no início do século XXI, impactam diretamente nas estratégias de produção e nas relações de trabalho. 0 gênero industrial calçadista, por necessitar de uma grande quantidade de mão de obra, é um dos mais atingidos pelas novas organizações produtivas flexíveis. Mas não devemos deixar de considerar que, embora a flexibilidade seja a marca das mudanças produtivas para essa atividade, em função das demandas por produtividade, ainda coexistem formas flexíveis com linhas de produção fordistas. 
70 o território, estabelecendo redes de articulações complexas, a desenharem uma intrincada conexão que envolvem agentes e ações em diversos tamanhos e escalas. No Brasil, essas mudanças foram marcantes a partir da década de 1990, com a abertura econômica e a chegada de produtos mais competitivos do mercado internacional. É um movimento que fez a indústria de calçados nacional alterar seus padrões territoriais de ocupação e o alcance dos circuitos espaciais produtivos, o que atingiu tanto áreas novas, incorporadas aos processos de produção, como as regiões de fabricação tradicional, a exemplo dos estados de São Paulo e Rio Grande do Sul.

71

este artigo, avaliamos os efeitos dessas mudanças no sistema industrial localizado de calçados de Franca, no estado de São Paulo. Constatamos que, com esse processo de reestruturação, o SIL não fica indiferente às novas forças de aceleração dos objetos e dos fluxos, decorrentes da hegemonia de interesses competitivos que buscam reduzir os custos de produção pela via da disjunção funcional e da precarização nas relações de trabalho. Do ponto de vista territorial, instaura-se em Franca uma mobilidade geográfica sem precedentes, a articular diversas escalas e integrar sistemas urbanos e regionais por meio de uma rede de relações comandadas por investimentos produtivos ávidos por valorização.

Ressalta-se os efeitos dessas mudanças sobre a centralidade produtiva exercida por Franca em municípios do estado de São Paulo, mas também em Minas Gerais, no Ceará e na Bahia, onde as empresas francanas instalam suas filiais de produção. Para o caso mineiro, destacado neste texto, o exemplo é emblemático, pois condiciona a expansão da área de influência direta das empresas industriais calçadistas, tornando complexa a divisão inter-regional do trabalho. Assim, como consequência dos aspectos concernentes à reestruturação produtiva e seus impactos sobre a articulação entre cidades na divisa dos estados de São Paulo e Minas Gerais, expande-se a "mancha regional" de influência de Franca e o alcance espacial do seu SIL de calçados.

73 Mesmo que todas essas modificações reforcem o dinamismo econômico, acelerem os fluxos migratórios e incorporem diferentes áreas aos processos produtivos industriais da região em análise, não podemos esquecer que o processo simboliza os novos conteúdos de uma reestruturação pautada no aumento da produtividade pela via da redução de custos, o que implica na ampliação da precarização do trabalho e no acirramento dos traços de desigualdade urbano e regional. Refletir sobre as vantagens e os limites dessa experiência para a sociedade na região é um desafio que deve ser priorizado.

\section{BIBLIOGRAFIA}

BARBOSA, Agnaldo de Sousa. Atuação pública e promoção da eficiência coletiva em arranjos produtivos locais - a experiência do polo industrial de Franca-SP. São Paulo Editora UNESP, 2016, p. 142.

Disponível em: <http://books.scielo.org/id/fm24q/epub/barbosa-9788568334768.epub>. Acesso em: 02 jan, 2019. 
BECATTINI, G. Dal settore industriale al “distretto" industriale. Alcune considerazione sull'unitá d'indagine dell'economia industriale. Rivista di economia política industriale, v. 5, n. 1, p.7-22, 1979. BENKO, George. Economia, espaço e globalização na aurora do século XXI. 2. Ed. São Paulo: Hucitec/ Annablume, 1999. 266p.

BRAGA FILHO, Hélio. A reorganização da indústria de calçados de Franca. FACEF Pesquisa, Franca, SP, v. 3, n. 2, p. 99-124, 2000.

BRASIL. MINISTÉRIO do Trabalho e Emprego - MTE. Relação Anual de Informações Sociais ação Anual de Informações Sociais - RAIS. Brasília: disponível em <http://bi.mte.gov.br/scripts10/ dardoweb.cgi>. Acesso em: 04 maio, 2018.

COSTA, E. J M. Arranjos produtivos locais, políticas públicas e desenvolvimento regional. Brasília: Mais Gráfica Editora, 404p, 2010.

FISHER, André. Industrie et espace géographique: introduction à la geógraphie industrielle. Paris: Masson, 137p, 1994.

NAVARRO, Vera Lúcia. Trabalho e trabalhadores do calçado: a indústria calçadista de Franca (SP): das origens artesanais à reestruturação produtiva. São Paulo: Expressão Popular, 304p, 2006.

MÉNDEZ, R. La telaraña financiera : una geografía de la financiarización y sus crisis. Santiago : RIL - Instituto de Estudos Urbanos y Territorialies UC, 2018.

MORAES, Jorge L. Amaral de; SCHNEIDER, S. Sistemas produtivos localizados (SPLs) como mecanismo de regulação e governação das dinâmicas socioeconômicas dos territórios. REDES, Santa Cruz do Sul, RS, v. 16, n. 1, p. 90 - 10, jan./abr. 2011.

LIPIETZ, Alain. Miragens e milagres: Problemas da Industrialização no Terceiro Mundo. São Paulo: Nobel, 1988. 231p.

PEREIRA JÚNIOR, Edilson. Território e economia política: uma abordagem a partir do novo processo de industrialização no Ceará. São Paulo: Cultura Acadêmica, 478p, 2012.

A indústria de calçados no Brasil diante da reestruturação territorial e produtiva. In: SPOSITO, E. S. (Org.). o novo mapa da indústria no início do século XXI: diferentes paradigmas para leitura das dinâmicas territoriais do estado de São Paulo. 1. Ed. São Paulo: Editora Unesp Digital, p. $153-200,2015$.

PYKE, F ; BECATTINI, G ; SENGERBERBER, W. Industrial districts and inter-firm co-operation in Italy. 2. Ed. Geneva: IILS, 1992.

REIS, José. Os espaços da indústria: a regulação econômica e o desenvolvimento local em Portugal. Porto, Portugal: Edições Afrontamento, 1992.

Estado, Mercado e Comunidade: A economia portuguesa e a governação contemporânea. Revista Crítica de Ciências Sociais, v. 70, p. 81-100, 2004. Disponível em:< http:// rccs.revues.org/1050>. Acesso em: 12 jun, 2017.

SANTOS, Milton. SILVEIRA, María Laura. O Brasil: Território e sociedade no início do século XXI. 9. Ed. Rio de Janeiro: Record, 476 p, 2013.

SELINGARDI-SAMPAIO, Silvia. Indústria e território em São Paulo: a estruturação do Multicomplexo Territorial Industrial Paulista: 1950-2005. Campinas, SP: Alínea, 480p, 2009.

SFORZI, Fabio. The quantitative importance of Marshallian industrial districts in the Italian economy. In : PYKE, F ; BECATTINI, G ; SENGERBERBER, W. Industrial districts and inter-firm cooperation in Italy. 2. Ed. Geneva: IILS, p.160-184, 1992. 
SINDICATO DA INDÚSTRIA DE CALÇADOS DE FRANCA. Relatório mensal: Nicc polo Franca. Franca, SP. 2019. Disponível em: <http://www.sindifranca.org.br/estatisticas.html>. Acesso em: 15 mar. 2019.

SUZIGAN, Wilson et al. Clusters ou Sistemas Locais de Produção: mapeamento, tipologia e sugestões de políticas. Revista de Economia Política, Porto Seguro, v. 24, n. 4, out./dez, 2004.

SOJA, Edward W. Geografias pós-modernas: a reafirmação da teoria social crítica.

Tradução: Vera Ribeiro. Rio de Janeiro: Jorge Zahar, 1993.

TRIGILIA, Carlo. Work and politics in the Third Italy's industrial districts. In : PYKE, F;

BECATTINI, G; SENGERBERBER, W. Industrial Districts and inter-firm co-operation in Italy. 2.ed.

Geneva: IILS, p.160-184, 1992.

VELTZ, Pierre. Le nouveau monde industriel. Paris: Éditions Galimard, 2008.

\section{NOTAS}

1. Além de Franca, o estado de São Paulo destaca os SILs de Birigui (especializado na produção de calçados infantis) e Jaú (especializado na produção de calçados femininos).

2. As bancas são unidades produtivas (oficinas de trabalho) que prestam serviços à indústria, em diversas etapas produtivas, podendo ser especializadas em determinada etapa ou produzir o calçado por completo. Além disso, seu porte é variado (NAVARRO, 2006).

3. Como assevera Barbosa (2016), com o choque de competitividade engendrado pela emergência da nova ordem econômica global e as baixas barreiras à entrada de produtores no setor, os trabalhadores que eram demitidos das maiores empresas (como a Calçados Terra, Pestalozzi, Francano, Guaraldo, Paragon e M 2000) passaram a montar suas próprias fábricas, marcando a conversão de operários à proprietários, embora sem nenhuma formação ligada à administração.

4. Entre os fatores de atração das empresas calçadistas para municípios de Minas Gerais, podemos destacar o ICMS de $2 \%$ cobrado desde 2017, segundo o ofício no05/2017/GAB/SUTRI. Enquanto isso, o ICMS sobre calçados no estado de São Paulo está em 7\%.

5. Segundo entrevista realizada em maio de 2017 com um produtor de calçados: "[...] essas cidades têm os benefícios delas... Cara, se você for pegar aqui, tem lugar que você travessar o estado de Minas, com meia hora você travessa o estado de Minas. Travessou, o estado de Minas, montou o barracão, já paga um salário diferente. [...] Claraval, por exemplo, você não vai gastar meia hora, que é Minas. Capetinga, Sacramento.... Lá a diferença de salário que eles paga daqui é uma diferença quase de 50\%...".

\section{RESUMOS}

O presente trabalho aborda o processo de reestruturação produtiva e territorial do sistema industrial localizado de calçados (SIL) de Franca, em São Paulo, que enfrenta desde os anos de 1990 uma série de mudanças vinculadas ao aumento da produtividade pela via da redução de custos. O SIL não fica indiferente às novas forças de aceleração dos objetos e dos fluxos decorrentes da hegemonia de interesses competitivos. Do ponto de vista territorial, instaura-se 
em Franca uma mobilidade geográfica sem precedentes, capaz de integrar sistemas urbanos e regionais por meio de uma rede de relações que ampliam a área de influência direta das empresas calçadistas, tornando complexa a divisão espacial do trabalho no local.

Ce travail s'approche du processus de restructuration productive et territoriale, du Système Industriel Localisé (SIL) chaussures de Franca, à São Paulo, qui, depuis les années 90, a été confrontée à une série de changements liés à l'augmentation de la productivité par la réduction des coûts. Le SIL n'est pas indifférent aux nouvelles forces d'accélération des objets et flux découlant de l'hégémonie des intérêts compétitifs. Du point de vue territorial, une mobilité géographique sans précédent est établie à Franca, capable d'intégrer les systèmes urbains et régionaux à travers un réseau de relations qui élargit la zone d'influence directe des entreprises de chaussures, rendant la division spatiale du travail complexe sur place.

El presente trabajo aborda el proceso de reestructuración productiva y territorial del sistema industrial localizado de calzados (SIL) de Franca, en São Paulo, que enfrenta desde los años 1990 una serie de cambios vinculados al aumento de la productividad por la vía de la reducción de costos. El SIL no queda indiferente a las nuevas fuerzas de aceleración de los objetos y de los flujos derivados de la hegemonía de intereses competitivos. Desde el punto de vista territorial, se instaura en Franca una movilidad geográfica sin precedentes, capaz de integrar sistemas urbanos y regionales a través de una red de relaciones que amplían el área de influencia directa de las empresas de calzado, haciendo compleja la división espacial del sector, trabajo en el lugar.

This paper approaches the process of productive and territorial restructuring of the Located Industrial System (LIS) of shoes of Franca, in São Paulo, that faces since the years of 1990 a series of changes linked to the increase of the productivity by way of the reduction of costs. The LIS is not indifferent to the new forces of acceleration of objects and flows resulting from the hegemony of competing interests. From the territorial point of view, is instated in Franca an unprecedented geographical mobility, capable of integrating urban and regional systems through a network of relationships that expand the area of direct influence of footwear companies, making complex the spatial division of labour in the place.

\section{ÍNDICE}

Mots-clés: système industriel localisé, Franca, Industrie de la chaussure, Sao Paulo, restructuration urbaine régionale.

Palavras-chave: sistema industrial localizado, Franca, indústria de calçados, reestruturação urbano regional.

Palabras claves: sistema industrial localizado, Franca, industria del calzado, reestructuración urbana regional

Keywords: localized industrial system, Franca, footwear industry, regional urban restructuring.

\section{AUTORES}

\section{JOSÉ EUDÁZIO HONÓRIO SAMPAIO}

Mestrando no Programa de Pós-Graduação em Geografia da Universidade Estadual do Ceará (UECE) e graduado em Geografia Bacharelado pela mesma instituição. É Bolsista de Mestrado do Conselho Nacional de Desenvolvimento Científico e Tecnológico (CNPq). E-mail: eudaziosampaio@gmail.com. 


\section{EDILSON ALVES PEREIRA JÚNIOR}

Professor Adjunto da Universidade Estadual do Ceará (UECE). Bolsista Produtividade CNPq 2. Doutor em Geografia pela Universidade Estadual Paulista (UNESP - Presidente Prudente). Coordena o Laboratório de Estudos do Território e da Urbanização - LETUr.

E-mail: edilsonapjr@hotmail.com. 